\title{
Unproductive by choice: substitution and the slowdown in aggregate productivity growth in the United States
}

\author{
Zach Flynn*
}

December 31, 2019

\begin{abstract}
I propose a new decomposition of aggregate total factor productivity. I model productivity as an index of unmeasured factors of production, and decompose the conditional factor demand for this index. With this model of productivity, changes in the price of labor or capital cause substitution to or from productivity. I study whether such changes explain the slowdown in US productivity growth from 2005 to 2016. I find that the declining growth rate of the effective price of labor and capital encouraged substitution away from productivity. If labor and capital prices had remained constant, productivity growth would be accelerating.
\end{abstract}

Keywords: aggregate productivity, productivity measurement, endogenous productivity growth

JEL Codes: E23, D24, E13

${ }^{*}$ E-mail: zlflynn@gmail.com. This research did not receive any specific grant from funding agencies in the public, commercial, or not-for-profit sectors. 


\section{Introduction}

Total factor productivity growth has decelerated in the past decade. The causes and consequences of the slowdown matter for long run economic welfare. The two leading explanations are that technological improvement itself has truly slowed down or that productivity is increasingly mismeasured so that our measures of productivity do not capture the full value of new innovations. If the fall in the growth rate of productivity is the result of slowing technological growth, welfare-per-person is improving less rapidly now than it used to. If the declining growth rate is illusory, the result of some error in how we measure productivity, it may not matter at all ${ }^{1}$. I propose a model of productivity that offers a different explanation than these two leading theories.

I model productivity as a function of the factors of production that we do not include in the production function. In this model, there is a new avenue through which productivity can rise or fall. As the prices of labor and capital change, the economy will substitute to or from productivity. Substitution has a different economic consequence than either slowing technological growth or mismeasurement. If productivity is mismeasured, there is no slowdown. If technological progress has slowed, then perhaps either the economy no longer innovates as rapidly as it once did (Gordon, 2016) or it is inefficiently allocating resources (Baqaee and Farhi, 2019). In this paper, I argue there is a slowdown in productivity growth but it is not from slowing technological progress: the factors of production that determine productivity have a higher effective price relative to capital and labor than they did previously. Productivity is growing more slowly because the economy is substituting away from productivity and towards capital and labor.

This factor model of productivity, while new as an explicit model used for empirical measurement, goes back to at least Griliches and Jorgenson (1967). They argue that there would be little left of the productivity residual if we could accurately and fully account for all the various factors of production in the economy. They memorably call productivity, "the measure of our ignorance", because it reflects our lack of knowledge about how output is produced not necessarily technological progress. What I add to the literature is a simple framework for modeling how the unmeasured factors of production change in response to changes in the price of labor and capital.

A related part of the productivity measurement literature aims to pull various factors out of the Solow residual by using observable proxies for factors traditionally included in productivity. The growth literature on human capital accumulation pulls human capital out of the productivity residual. The literature on intangible capital and factor utilization (Basu and Kimball, 1997; Fernald, 2014; Fernald and Wang, 2016) does the same for these difficult-tomeasure factors. Instead of trying to pull individual factors out of productivity, I assume productivity is determined by many unobserved factors and model how an index of those factors changes in response to other changes in the economy.

My framework is entirely within the standard neoclassical model. I model the economy with

\footnotetext{
${ }^{1}$ See Syverson (2017) and Byrne, Fernald, and Reinsdorf (2016) for a comparison of these two competing explanations for falling productivity growth.
} 
a representative firm. Returns to scale are constant. Prices are equal to marginal cost. The firm has a Cobb Douglas production function. As a consequence, my measure of productivity itself is no different than Solow (1957)'s measure so I am not arguing productivity is typically mismeasured. The difference in this paper is in what changes in the economy influence productivity.

Because productivity is an index of unobserved factors, it has a conditional demand function. I develop a new decomposition of productivity based on this function. The decomposition has five terms: changes in the effective price ${ }^{2}$ of labor, changes in the effective price of capital, changes in the effective price of productivity, changes in aggregate demand, and changes in the overall technology of using labor and capital. I use this decomposition to measure the extent to which substitution from productivity and to labor and capital is behind the slowdown in productivity growth. I find that the growth rate of the effective price of labor and capital has declined over the past decade. If it had not declined, productivity growth would have accelerated. The decrease in productivity growth is not a sign of a slowdown in technological progress because I find the cost to the economy of producing productivity is actually falling at an accelerating rate. The decrease in productivity growth is the result of changes in relative factor prices.

Section 2 introduces the factor model of productivity, deriving the factor demand equation for productivity and the decomposition of productivity that forms the basis for my empirical analysis.

Section 3 uses this decomposition to study the economy of the United States from 1987 to 2016. I decompose the causes of the recent decline in total factor productivity from 2005 to 2016. I find two main trends: (1) the effective prices of labor and capital are growing at a slower rate than they used to so the economy is substituting from productivity to labor and capital and (2) productivity growth has decelerated even as the price of productivity (an index of the prices of the unobserved factors of production) has fallen rapidly, suggesting that less demand for productivity is behind the productivity slowdown.

Section 4 concludes with the implications of this interpretation of the recent slowdown in productivity growth.

\section{The factor model of productivity}

\subsection{What is productivity?}

In the neoclassical growth model and other standard macroeconomic models (like the endogenous growth models following Romer 1986), productivity is an exogenous process: it is a shock to the economy that affects other decisions, not an equilibrium outcome itself. Productivity in period $t$ is $A_{t}$ and in period $(t+1)$ productivity is $A_{t+1}=\left(1+g_{t}\right) A_{t}$ where $g_{t}$ is an exogenous growth rate.

\footnotetext{
2 "Effective price" is the ratio of an input price to the corresponding output elasticity, a buck-per-bang measure.
} 
I model productivity differently. I suppose that if we were to accurately measure all factors of production in the economy that there would not be a residual in the production relationship,

$$
\text { Output }=F \text { (Inputs) } .
$$

Productivity is then the part of output that we cannot explain with the set of inputs we measure. But this part of output is also produced using factors of production because all output is produced by some factor. The main implication is that shocks that affect the wage of labor or the rental rate of capital can result in changes to productivity. This cannot happen if we treat productivity as an exogenous sequence.

I show that we can measure the cost of productivity and the other parameters of the economy's cost minimization problem even though we do not observe the individual inputs that make up productivity. I then use the conditional factor demand function for productivity to understand how changes in wages or the price of capital affect productivity.

\subsection{The pure factor production function}

Let $Q$ be output, $L$ be labor, $K$ be capital, and $Z \in \mathbb{R}^{M}$ be a vector of unobserved factors of production. The aggregate production function is Cobb Douglas,

$$
Q=F_{0} \times L^{\theta_{L}} K^{\theta_{K}} \times \prod_{m=1}^{M} Z_{m}^{\gamma_{m}} .
$$

Suppose the economy minimizes its costs like a representative firm would,

$$
\min _{L, K, Z} W_{L} L+W_{K} K+W_{Z}^{\top} Z \quad \text { sT: } \quad F_{0} \times L^{\theta_{L}} K^{\theta_{K}} \times \prod_{m=1}^{M} Z_{m}^{\gamma_{m}} \geq Q .
$$

I model productivity $(A)$ as the contribution of unobserved factors of production to output,

$$
A=\prod_{m=1}^{M} Z_{m}^{\gamma_{m}} .
$$

The economy will minimize the cost of producing $A$ from the $Z$ inputs given whatever decision it makes about labor and capital. So we can define the cost of producing the index $A$,

$$
C(A)=\min W_{Z}^{\top} Z \quad \mathrm{ST}: \quad \prod_{m=1}^{M} Z_{m}^{\gamma_{m}} \geq A .
$$

From textbook algebra on the cost function of the Cobb Douglas production function, $C(A)$ has the following functional form,

$$
C(A)=C_{0}\left(W_{Z}, \gamma\right) A^{\frac{1}{\sum_{m} \gamma_{m}}} .
$$


Define $\theta_{A}=\sum_{m} \gamma_{m}$. We can think of the sum of the $Z$ output elasticities as the output elasticity of productivity.

The economy's cost minimization problem in terms of $(L, K, A)$ is then,

$$
\min _{L, K, A} W_{L} L+W_{K} K+C_{0}\left(W_{Z}, \gamma\right) A^{\frac{1}{\theta_{A}}} \quad \mathrm{ST}: \quad F_{0} \times L^{\theta_{L}} K^{\theta_{K}} A \geq Q
$$

Equivalently, we can define $\widetilde{A}=A^{\frac{1}{\theta_{A}}}$ and treat $\widetilde{A}$ symmetrically to $(L, K)$,

$$
\min _{L, K, \widetilde{A}} W_{L} L+W_{K} K+C_{0}\left(W_{Z}, \gamma\right) \widetilde{A} \quad \mathrm{sT}: \quad F_{0} \times L^{\theta_{L}} K^{\theta_{K}} \widetilde{A}^{\theta_{A}} \geq Q
$$

\subsection{Measuring productivity and the parameters of the cost function}

I make two assumptions that are firmly in the tradition of the neoclassical model.

Assumption 1. The price of the economy's output is equal to its marginal cost,

$$
P=\mathrm{MC} \text {. }
$$

Assumption 2. The production function has constant returns to scale,

$$
\theta_{L}+\theta_{K}+\sum_{m=1}^{M} \gamma_{m}=\theta_{L}+\theta_{K}+\theta_{A}=1
$$

I choose $F_{0}$ to normalize productivity so that its units remain constant even as $\theta_{L}$ and $\theta_{K}$ change. I set $F_{0}=L_{2012}^{-\theta_{L}} K_{2012}^{-\theta_{K}}$ where $L_{2012}$ is labor use in 2012 and $K_{2012}$ is capital use in 2012. Productivity is then always the amount of output that would be produced if $L=L_{2012}$ and $K=K_{2012}$.

Let $\lambda$ be the Lagrange multiplier on the economy's output constraint in its cost minimization problem. The first order conditions with respect to $L$ and $K$ give,

$$
\frac{W_{L} L}{\lambda \times Q}=\theta_{L}, \quad \frac{W_{K} K}{\lambda \times Q}=\theta_{K}
$$

From the envelope theorem, $\lambda$ is marginal cost. Therefore, by Assumption $1, \lambda=P$. So,

$$
\frac{W_{L} L}{P Q}=\theta_{L}, \quad \frac{W_{K} K}{P Q}=\theta_{K} .
$$

$\left(\theta_{L}, \theta_{K}\right)$ can then be measured using data on nominal output and spending on labor and capital. The first thing to notice is that $\left(\theta_{L}, \theta_{K}\right)$ would be measured in the same way regardless of whether we treated productivity as a factor or as an exogenous sequence of shocks. Because $A=Q F_{0}^{-1} L^{-\theta_{L}} K^{-\theta_{K}}$, the measure of productivity does not change with 
this model only the interpretation of it. My measure of productivity is exactly the classic Solow residual.

From Assumption 2, I recover $\theta_{A}$,

$$
\theta_{A}=1-\theta_{L}-\theta_{K}
$$

The first order condition with respect to $A$ then allows us to recover the last parameter of the economy's cost minimization problem, $C_{0}$.

$$
\frac{C_{0}}{\theta_{A}} A^{\frac{1-\theta_{A}}{\theta_{A}}}=\lambda F_{0} L^{\theta_{L}} K^{\theta_{K}}
$$

Because we can recover $A=Q F_{0}^{-1} L^{-\theta_{L}} K^{-\theta_{K}}$ given our measure of $\left(\theta_{L}, \theta_{K}\right)$ and because $\lambda=P$, I have the following measure of $C_{0}$,

$$
C_{0}=P \times F_{0} \theta_{A} L^{\theta_{L}} K^{\theta_{K}} A^{\frac{\theta_{A}-1}{\theta_{A}}}=P \times \theta_{A} \times \frac{Q}{A^{\frac{1}{\theta_{A}}}} .
$$

So all parameters of the economy's cost minimization problem can be measured.

\subsection{Conditional factor demand for productivity}

My goal is to understand the role of labor and capital prices in driving productivity growth. To do so, I decompose productivity using its conditional factor demand function. The decomposition allows us to write productivity as the product of cross-price effects (labor and capital prices), own-price effects (productivity prices), demand effects, and labor-capital technology effects.

It is useful to write the problem replacing $\widetilde{A}=A^{\frac{1}{\theta_{A}}}$ in the economy's cost minimization problem as mentioned above because the problem is then symmetric in three inputs,

$$
\min _{L, K, \widetilde{A}} W_{L} L+W_{K} K+C_{0} \widetilde{A} \quad \mathrm{ST}: \quad F_{0} L^{\theta_{L}} K^{\theta_{K}} \widetilde{A}^{\theta_{A}} \geq Q
$$

From the first order conditions, the conditional factor demand for $\widetilde{A}$ is,

$$
\widetilde{A}=\left(\frac{\theta_{L}}{W_{L}}\right)^{-\theta_{L}}\left(\frac{\theta_{K}}{W_{K}}\right)^{-\theta_{K}}\left(\frac{\theta_{A}}{C_{0}}\right)^{-\theta_{A}} \times \frac{\theta_{A} Q}{C_{0} F_{0}}
$$

Exponentiating both sides with respect to $\theta_{A}$, I then have the conditional factor demand for $A$,

$$
\begin{aligned}
A & =\left(\frac{\theta_{L}}{W_{L}}\right)^{-\theta_{A} \theta_{L}}\left(\frac{\theta_{K}}{W_{K}}\right)^{-\theta_{A} \theta_{K}}\left(\frac{\theta_{A}}{C_{0}}\right)^{-\theta_{A}^{2}} \times\left(\frac{\theta_{A} Q}{C_{0} F_{0}}\right)^{\theta_{A}} \\
& =\left(\frac{\theta_{L}}{W_{L}}\right)^{-\theta_{A} \theta_{L}}\left(\frac{\theta_{K}}{W_{K}}\right)^{-\theta_{A} \theta_{K}}\left(\frac{\theta_{A}}{C_{0}}\right)^{\theta_{A}\left(1-\theta_{A}\right)} \times Q^{\theta_{A}} \times F_{0}^{-\theta_{A}}
\end{aligned}
$$


Taking logs, the conditional factor demand decomposes productivity into terms corresponding to the effective price of the labor input, the effective price of the capital input, the effective price of productivity, output, and the baseline technology for labor and capital,

$$
\log A=\underbrace{\theta_{A} \theta_{L} \log \left(\frac{W_{L}}{\theta_{L}}\right)}_{\text {Effective labor price }}+\underbrace{\theta_{A} \theta_{K} \log \left(\frac{W_{K}}{\theta_{K}}\right)}_{\text {Effective capital price }}-\underbrace{\theta_{A}\left(1-\theta_{A}\right) \log \left(\frac{C_{0}}{\theta_{A}}\right)}_{\text {Effective productivity price }}+\underbrace{\theta_{A} \log Q}_{\text {Output }}-\underbrace{\theta_{A} \log F_{0}}_{\text {Baseline technology }}
$$

The first two terms capture the substitution effect. Increases in the effective price of labor and capital relative to productivity price increase productivity. The third term captures own price effects. Increases in the effective productivity price will lower productivity all else equal. The fourth term captures demand effects because this equation is the conditional factor demand so supply determinants of output are already incorporated. The model says larger economies are more productive for fixed effective prices mimicking results in the industrial organization literature on production theory (Flynn, 2019). The fifth term captures pure technological progress in using labor and capital. Naturally, improvements in technology $\left(F_{0}\right.$ decreasing) increase productivity.

\section{Productivity and its cost in the United States}

\subsection{Data}

I use annual data on the US economy from 1987 to 2016. All of the data is publicly available. I downloaded it from FRED at the St. Louis Federal Reserve. In Table 1, I tabulate exactly how each piece of data I use translates into the model's variables. The original data comes primarily from the Bureau of Labor Statistics.

All of the data, its source series, and my R code are available on Github at https://github . com/flynnzac/factprod-data/.

Table 1: Data and parameters

\begin{tabular}{lll}
\hline Parameter & Description & Series Name \\
\hline$P$, output price & Consumer Price Index/100 & CPIAUCNS \\
$Q$, output & Private Nonfarm Business Sector Output / P & MPU4910101 \\
$L$, labor & Private Nonfarm Hours Worked (by salary workers) & PRSCA \\
$W_{L}$, labor price & Total Private Nonfarm Business Sector Labor Compensation / L & MPU4910121 \\
$K$, capital & Private Nonfarm Business Sector Capital Services & MPU4910042 \\
$W_{K}$, capital price & Private Nonfarm Business Sector Capital Income / $K$ & MPU4910111 \\
\hline
\end{tabular}

The data I used can be fetched by visiting https://alfred.stlouis.org/series?seid= SERIESNAME where SERIESNAME is what appears in the Series Name column above. 
Figure 1: Productivity in the United States (1987-2016) (solid lines are smoothed by Tukey's smoothing and dashed lines are original series)

(a) Productivity

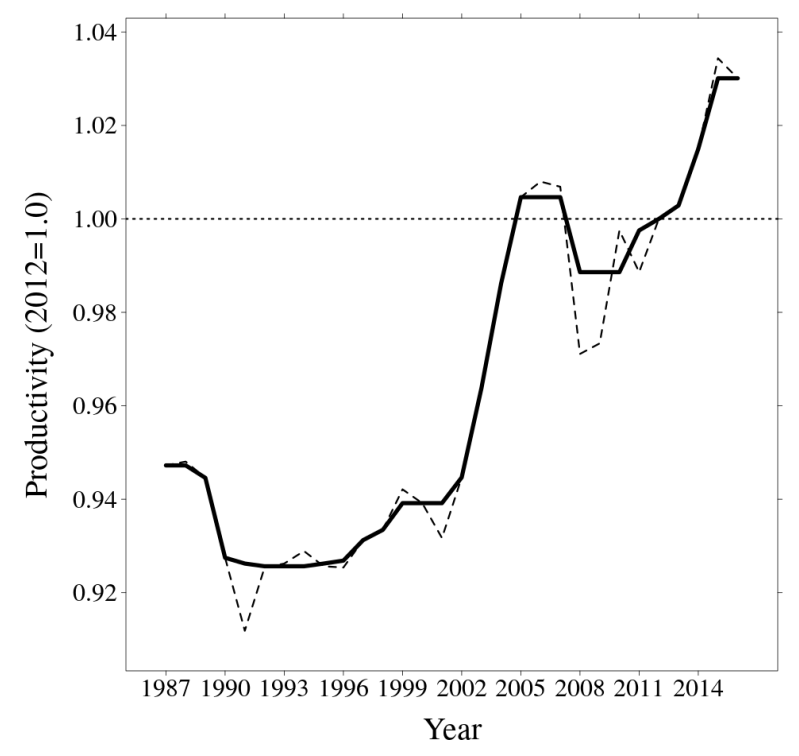

(b) Productivity Growth

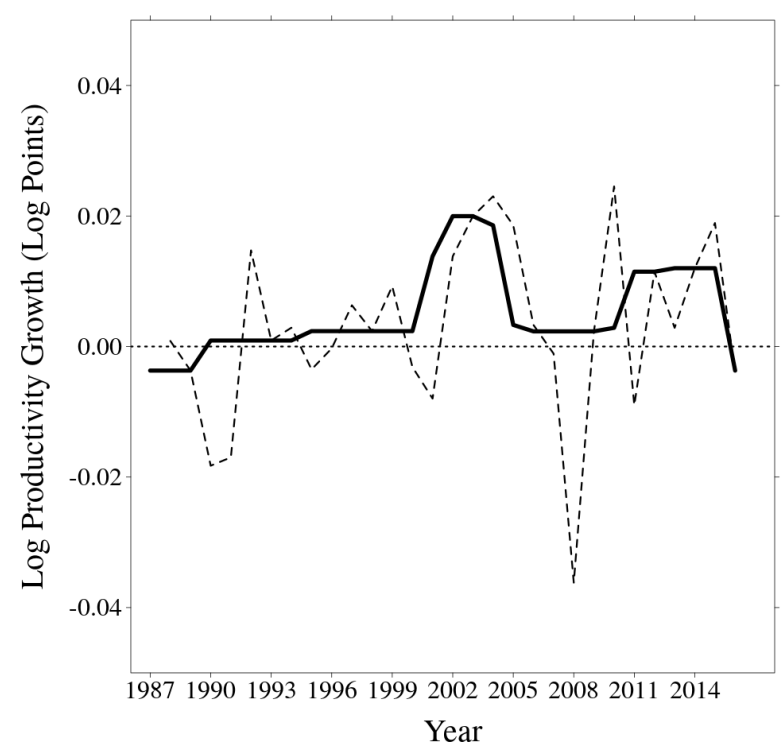

\subsection{Productivity growth from 1987-2016}

Total factor productivity grew sharply starting after the 2001 recession, before growth decelerated around 2005 (see Figure 1). The annual growth rate of productivity from 1987 to 2005 was $0.33 \%$. From 2005 to 2016, the annual growth rate of productivity was only $0.22 \%$. The annual growth rate dropped by a third. I decompose productivity using the model in Section 2 to understand the causes of this slowdown in productivity growth.

\subsection{Decomposition of productivity growth from 1987-2016}

I find the productivity slowdown is the result of a fall in demand for productivity. I demonstrate this result by showing that (1) the declining growth rate of effective price of labor and capital is causing substitution from productivity to labor and capital and (2) the price of the unobserved factors are declining at an accelerating rate, a sign that productivity is becoming significantly cheaper (technical progress), at the same time as the quantity purchased of the unobserved factors is growing at a slower rate.

The full decomposition is in Table 2.

\subsubsection{Declining effective prices of labor and capital}

Between 1987 and 2005 the effective price of labor increased at a rate of $0.15 \%$ annually, and the effective price of capital increased at a rate of $0.09 \%$. But between 2005 and 2016, the effective price of labor declined at a $0.03 \%$ annual rate and the effective price of capital increased at an annual rate of only $0.02 \%$. This drastic reduction in the growth rates of 
effective labor and capital prices caused substitution away from productivity and towards labor and capital, and it is a major driving force behind declining productivity growth. If the effective prices of labor and capital grew at the same rate after 2005 as they did before (holding all else constant), productivity would have grown $0.46 \%$ annually, more than $40 \%$ greater than it did from 1987 to 2005 . So productivity growth would be accelerating were it not for the declining growth rate of the effective price of labor and capital.

The reduction in productivity growth is then the result of substitution towards labor and capital as they became cheaper relative to productivity. If productivity were becoming more expensive - in an absolute sense as opposed to relative to capital and labor prices - this would still be an argument that technological stagnation in production of the unmeasured factors of production is behind declining productivity. But the cost of productivity is declining and the pace at which it is declining is accelerating.

\subsubsection{Falling cost of productivity}

Table 2 shows that a large fraction of the recent productivity growth there has been is, in fact, a consequence of the falling effective price of productivity, consistent with either technological progress in using the unobserved factors of production or more effective technology for supplying them. From 1987 to 2005, the price of productivity actually rose, rising by $0.24 \%$ on average annual. Between 2005 and 2016, the price of productivity term fell by $0.64 \%$ on average annually. So productivity is becoming increasingly cheap to produce. If everything else had remained constant, we would be seeing accelerating productivity growth instead of declining growth. And, if the cost of productivity had grown at the same rate as it had prior to 2005 , productivity would have substantially declined by $-0.59 \%$ annually from 2005 to 2016.

The cost of productivity has two components: (1) the technology of the unobserved factors of production $\left(\theta_{A}\right)$ and the price of the unobserved inputs $\left(W_{Z}\right)$. From Figure $3 \mathrm{~b}$, we can see that $\theta_{A}$ has barely changed at all from around 0.06 in the past thirty years. The falling cost of productivity is primarily driven by falling $W_{Z}$.

Because $W_{Z}$ is falling faster and productivity growth is slowing, we have that prices are declining and quantity supplied is growing at a decreasing rate. So demand for productivity must be growing less quickly than it did previously. Because if prices fall and quantity demanded shrinks, it must be that the demand curve shifts in. The decline in productivity growth is the result of lower demand for productivity.

The lower demand cannot be driven by a change in the technology of producing productivity because $\theta_{A}$ has remained constant over time. Instead, productivity demand is weaker because the effective prices of labor and capital are not growing as rapidly as they once did. 
Figure 2: Non-cost of productivity components of productivity (solid lines are smoothed by Tukey's method, dashed lines are original series, and dotted line is at 1.0)

(a) Effective price of capital component of productivity (Index: $2012=1.0$ )

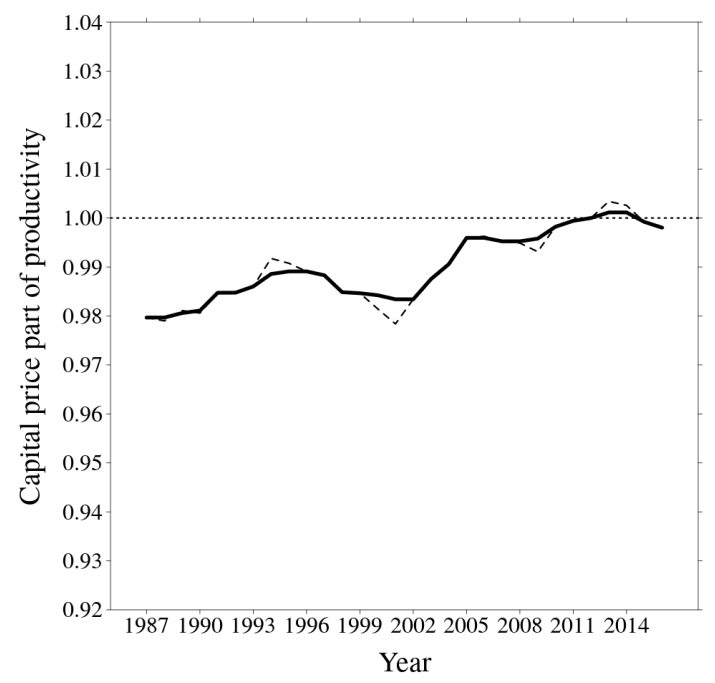

(c) Output component of productivity (Index: $2012=1.0)$

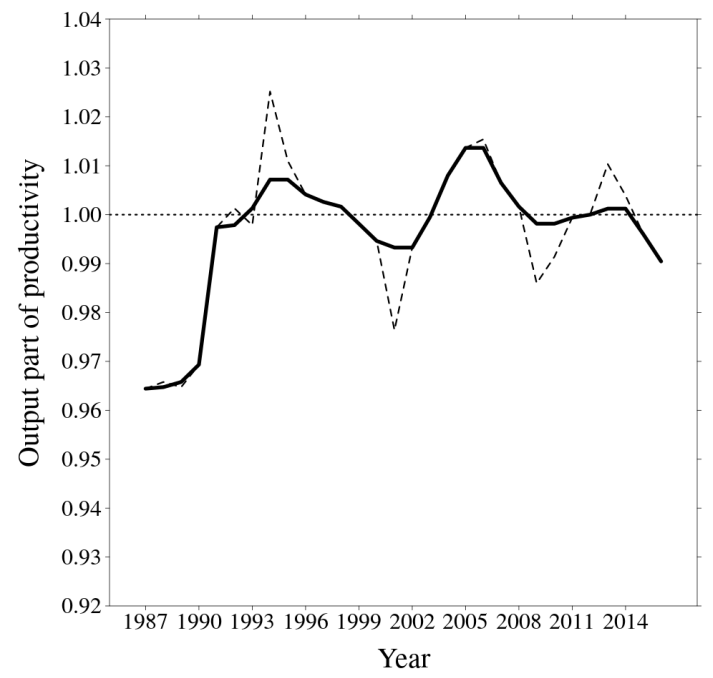

(b) Effective price of labor component of productivity (Index: $2012=1.0$ )

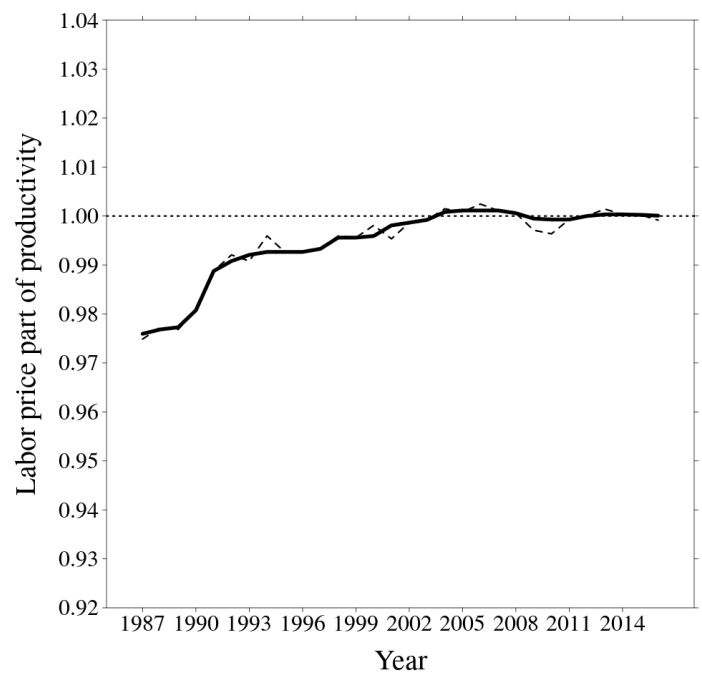

(d) Technical progress in labor and capital component of productivity (Index: $2012=$ 1.0)

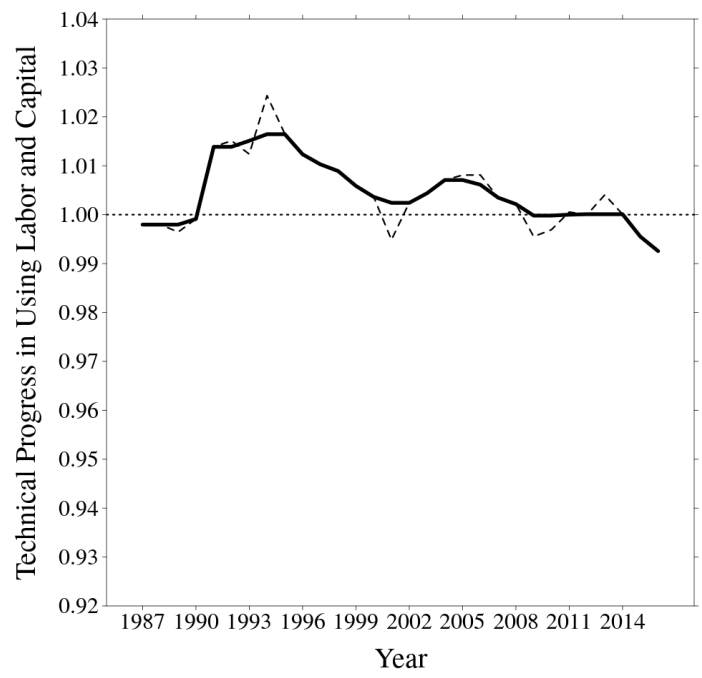


Table 2: Decomposition of productivity growth

\begin{tabular}{lrr}
\hline Part of productivity & Annual Growth Rate (1987-2005) & Annual Growth Rate (2006-2016) \\
\hline All & $0.33 \%$ & $0.22 \%$ \\
Labor Price & $0.15 \%$ & $-0.03 \%$ \\
Capital Price & $0.09 \%$ & $0.02 \%$ \\
Output & $0.28 \%$ & $-0.25 \%$ \\
Technical Progress & $0.06 \%$ & $-0.16 \%$ \\
Productivity Price & $0.24 \%$ & $-0.64 \%$ \\
\hline
\end{tabular}

Each row corresponds to a different term in the productivity decomposition. So the row for Technical Progress is $-\theta_{A} \times \log F_{0}$ (recall that decreases in $F_{0}$ reflect increases in laborcapital technology).

Figure 3: Cost of productivity and the elasticity of its inputs

(a) The falling effective price of productivity (solid lines are smoothed by Tukey's smoothing, dashed are original series, dotted line is at 1.0)

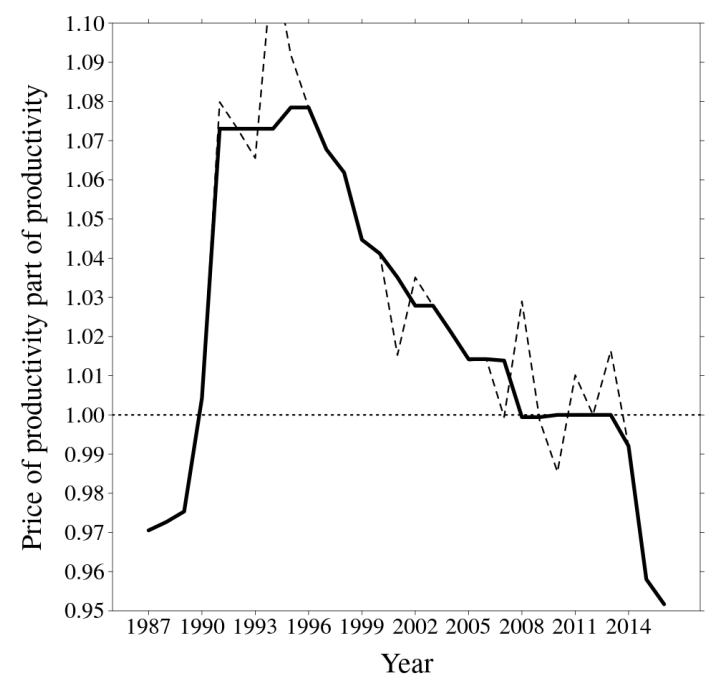

(b) $\theta_{A}$ over time

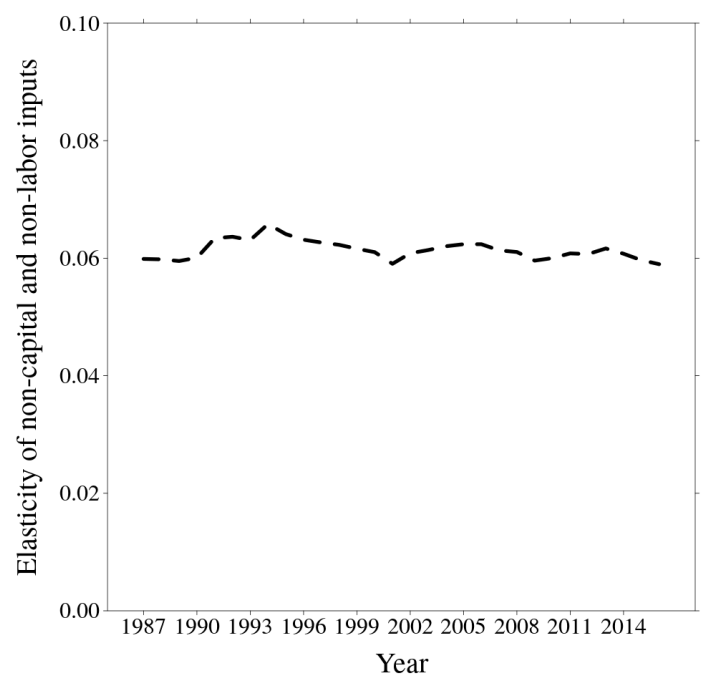




\section{What do these results imply about the slowdown in productivity growth?}

A prominent theory for the decline in productivity is that technology is improving more slowly than it used to (Gordon, 2016). But from the perspective of the model in this paper, this is not the whole story. The price of becoming more productive has fallen dramatically and has continued to decline without slowing down. But the growth rate of the effective price of labor and capital have declined, encouraging relatively more substitution towards those factors of production and away from productivity. The decline in the rate of productivity growth is not then a sign of technological stagnation, but a sign that labor and capital are relatively cheaper than they used to be. There is less benefit to the economy of being more productive even as the cost of being so falls.

In this paper, I developed a method of decomposing productivity supposing that it is produced by unobserved factors of production. I applied this decomposition to study productivity growth in the United States over the past thirty years. The analysis offered a new interpretation of part of the slowdown in productivity. It suggests that the slowdown is a reallocation across the various factors that determine the economy's output, not a decline in our technological capacity. 


\section{References}

Baqaee, D. and E. Farhi (2019). A short note on aggregating productivity. NBER Working Papers (25688).

Basu, S. and M. Kimball (1997). Cyclical productivity with unobserved input variation. NBER Working Papers (5915).

Byrne, D., J. Fernald, and M. Reinsdorf (2016). Does the united states have a productivity slowdown or a measurement problem? Brookings Papers on Economic Activity, 109-182.

Fernald, J. (2014). A quarterly, utilization-adjusted series on total factor productivity. Federal Reserve Bank of San Francisco Working Paper (2012-19).

Fernald, J. and C. Wang (2016). Why has the cyclicality of productivity changed? what does it mean? Federal Reserve Bank of San Francisco Working Paper Series (2016-07).

Flynn, Z. (2019). Identifying productivity when it is a factor of production. RAND Journal of Economics (Forthcoming).

Gordon, R. (2016). The Rise and Fall of American Growth: The U.S. Standard of Living since the Civil War. Princeton University Press.

Griliches, Z. and D. Jorgenson (1967). The explanation of productivity change. The Review of Economic Studies 34(3), 249-283.

Romer, P. (1986). Increasing returns and long-run growth. The Journal of Political Economy 94(5), 1002-1037.

Solow, R. (1957). Technical change and the aggregate production function. The Review of Economics and Statistics, 312-320.

Syverson, C. (2017). Challenges to mismeaurement explanations for the us productivity slowdown. Journal of Economic Perspectives 31(2), 165-186. 